\title{
Large scale synthesis of uniform nanotubes of a nickel complex by a solution chemical route
}

\author{
Lin Guo ${ }^{1 *}$, Chenmin Liu', Rongming Wang ${ }^{2}$, Huibin $\mathrm{Xu}^{1}$, Ziyu Wu ${ }^{3}$ Shihe Yang ${ }^{4 *}$ \\ 1. School of Materials Science and Engineering, Beijing University of Aeronautics and Astronautics, 100083, \\ China \\ 2. Electron Microscopy Laboratory and State Key Laboratory for Mesoscopic Physics, School of Physics, \\ Peking University, Beijing 100871, China \\ 3. Beijing Synchrotron Radiation Facility $\square$ Chinese Academy of Sciences, 100039, China \\ 4.Department of Chemistry, The Hong Kong University of Science and Technology, Clear Water Bay, \\ Kowloon, Hong Kong, China
}

\section{Supporting Information:}

\section{S-1. Experimental details}

All chemicals (Acros) used in this experiment were analytical grade and used without further purification. The growth of the $\mathrm{Ni}\left(\mathrm{NH}_{3}\right)_{6} \mathrm{Cl}_{2}$ nanotubes was carried out in solution phase. First, $4.7538 \mathrm{~g}(0.02 \mathrm{~mol}) \mathrm{NiCl}_{2} \bullet 6 \mathrm{H}_{2} \mathrm{O}$ and $6.66 \mathrm{~g}$ PVP $\left(\mathrm{M}_{\mathrm{W}}\right.$ 40,000) were dissolved in $125 \mathrm{ml}$ ethylene glycol (EG) by intensive stirring and sonication until a homogenous transparent grass-green solution was obtained. $10 \mathrm{ml}$ hydrazine monohydrate (50\% Vol. AR) was added dropwise to the well-stirred mixture at room temperature by simultaneous vigorous agitation. The solution turned turbid and sky-blue. The stirring process lasted for at least $1 \mathrm{~h}$ after finishing the dropping in order for the reaction to complete. The mixture was subsequently heated to the boiling point of ethylene glycol (EG) for refluxing $\left(\sim 197^{\circ} \mathrm{C}\right)$. Numerous bubbles formed in the flask. After refluxing for $5 \mathrm{~h}$, the color of the solution turned from sky-blue to orange and a kind of light violet precipitate could be achieved. Centrifugation was used to separate the precipitate, which was rinsed with absolute ethanol for 8 times. Subsequently, the volatile solvent was evaporated in vacuum at $80^{\circ} \mathrm{C}$ and finally a loose violet powder was obtained. These as-prepared products were used for characterization.

X-ray powder diffraction (XRD, Rigaku, Dmax2200, Cu-k $\alpha$ ) was used for the structural determination. Further microstructural and elemental analyses were performed using Scanning electron microscopy (SEM) (JSM-5800 with accelerating voltage of $15 \mathrm{kV}$ ) and analytical transmission electron microscopy (TEM) (Tecnai F30 TEM with field emission gun and accelerating voltage of $300 \mathrm{kV}$, FEI Company). The EELS spectrum was recorded in diffraction mode with an energy dispersion of $1.0 \mathrm{eV} /$ channel using the Gatan image filter (GIF) system attached to the Tecnai F30 TEM. The infrared spectrum was recorded in a Nicolet 560 infrared spectrometric analyzer.

EXAFS measurements were carried out at $\mathrm{Ni} \mathrm{K}$ edge in the transmission mode at the XAFS station (beam line 1W1B) of Beijing Synchrotron Radiation Laboratory. The storage ring was run at the typical energy of $2.2 \mathrm{GeV}$ with the circulatory current decreasing approximately from $135 \mathrm{~mA}$ to $80 \mathrm{~mA}$ during a time span of 8 hours. To suppress the higher harmonics, a detuning of $30 \%$ was performed between the double crystals $\mathrm{Si}(111)$ monochromator. The 
incidence and transmission $x$-ray intensities were detected by an ion chamber filled by $25 \%$ argon-doped nitrogen mixture. They were installed in front of and behind the sample respectively.

\section{S-2. Additional data showing the composition of the nickel complex nanotubes}

\subsection{EELS}

The chemical composition of an individual nickel complex nanostructure is determined by spatial-resolved electron energy loss spectroscopy (EELS), as shown in Fig. S1. The spectrum exhibits pronounced peaks at about $200 \mathrm{eV}, 284$ $\mathrm{eV}, 401 \mathrm{eV}$ and $855 \mathrm{eV}$, corresponding to the characteristic L-shell ionization edge of $\mathrm{Cl}, \mathrm{K}$ edges of $\mathrm{C}$ and $\mathrm{N}$, and $\mathrm{L}$ edge of $\mathrm{Ni}$, respectively. The carbon signal comes from the supporting grid. The calculated atomic $\mathrm{Cl}: \mathrm{N}: \mathrm{Ni}$ ratio is 3.55:15.1:5.99, which is the compositive effect of the mixture of $\mathrm{Ni}\left(\mathrm{NH}_{3}\right)_{6} \mathrm{Cl}_{2}$ and $\mathrm{Ni}\left(\mathrm{N}_{2} \mathrm{H}_{4}\right)_{2} \mathrm{Cl}_{2}$. The relatively higher $\mathrm{Ni}$ content lies in the fact that some $\mathrm{Ni}$ forms due to the electron beam-sensitivity of $\mathrm{Ni}\left(\mathrm{N}_{2} \mathrm{H}_{4}\right)_{2} \mathrm{Cl}_{2}$.

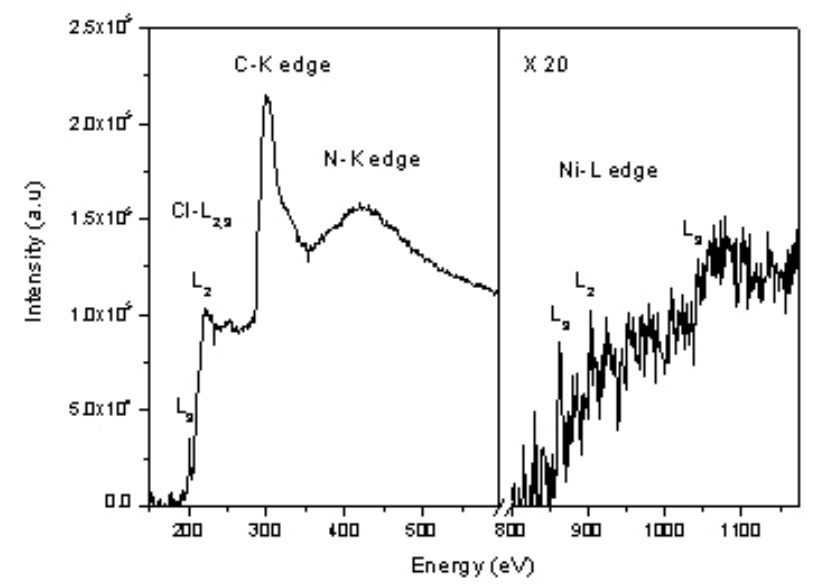

Fig. S1: EELS spectra of a single nickel complex nanotube.

\section{$2.2 X A F S$}

X-ray absorption spectroscopy (XAS) is a local technique of analysis based on the excitation of electronic transition from an inner level to outer unoccupied states. The photoabsorption process yields information on the local electronic structure and coordination environment around the absorbing atom. XAS techniques such as EXAFS (Extended X-ray Absorption Fine Structure) have been used extensively to investigate the local structure in the interior and at the surface, as well as bonding information of a variety of solid-state materials

As a reference, Table S1 gives the coordination numbers and bond lengths for the first and the second shell of $\mathrm{Ni}\left(\mathrm{NH}_{3}\right)_{6} \mathrm{Cl}_{2}$ derived from the XRD measurements.

Fig. S2 shows the XAFS signal in R space. The second and third peaks correspond to coordination shells located between $0.2 \mathrm{~nm}$ and $0.35 \mathrm{~nm}$. This can not be directly resulted from $\mathrm{Ni}\left(\mathrm{NH}_{3}\right)_{6} \mathrm{Cl}_{2}$ as its next-nearest neighbour atoms are located at $0.43 \mathrm{~nm}$ (see Table S1). Therefore we come to the conclusion that the nano-sample contains compound other than $\mathrm{Ni}\left(\mathrm{NH}_{3}\right)_{6} \mathrm{Cl}_{2}$. From the results of XRD and EELS, it is most likely to be $\mathrm{Ni}\left(\mathrm{N}_{2} \mathrm{H}_{4}\right)_{2} \mathrm{Cl}_{2}$, in which the second shell contains two $\mathrm{Cl}$ atoms at about $0.26 \mathrm{~nm}$ and the third shell four $\mathrm{N}$ atoms at about $0.31 \mathrm{~nm}$. This leads us to rebuild a mixed local structural model from two compounds, namely $\mathrm{Ni}\left(\mathrm{NH}_{3}\right)_{6} \mathrm{Cl}_{2}$ and $\mathrm{Ni}\left(\mathrm{N}_{2} \mathrm{H}_{4}\right)_{2} \mathrm{Cl}_{2}$. We calculated the EXAFS signal using FEFF 7.0 code, then performed the fitting to the experimental signal in $\mathrm{R}$ space up to the third shell, and got a very good agreement. Our fitting results are shown in Table $\mathrm{S} 2$. The first shell coordination number is about 5.5, indicating that the sample mainly consists of $\mathrm{Ni}\left(\mathrm{NH}_{3}\right)_{6} \mathrm{Cl}_{2}$ with some proportion of $\mathrm{Ni}\left(\mathrm{N}_{2} \mathrm{H}_{4}\right)_{2} \mathrm{Cl}_{2}$. The further fitting results of the second and third shells (see Table $\mathrm{S} 2$ for details) have confirmed that the nanotube sample contains both $\mathrm{Ni}\left(\mathrm{NH}_{3}\right)_{6} \mathrm{Cl}_{2}$ and $\mathrm{Ni}\left(\mathrm{N}_{2} \mathrm{H}_{4}\right)_{2} \mathrm{Cl}_{2}$; the former comprises the tube walls and the latter is enclosed inside the tubes. 


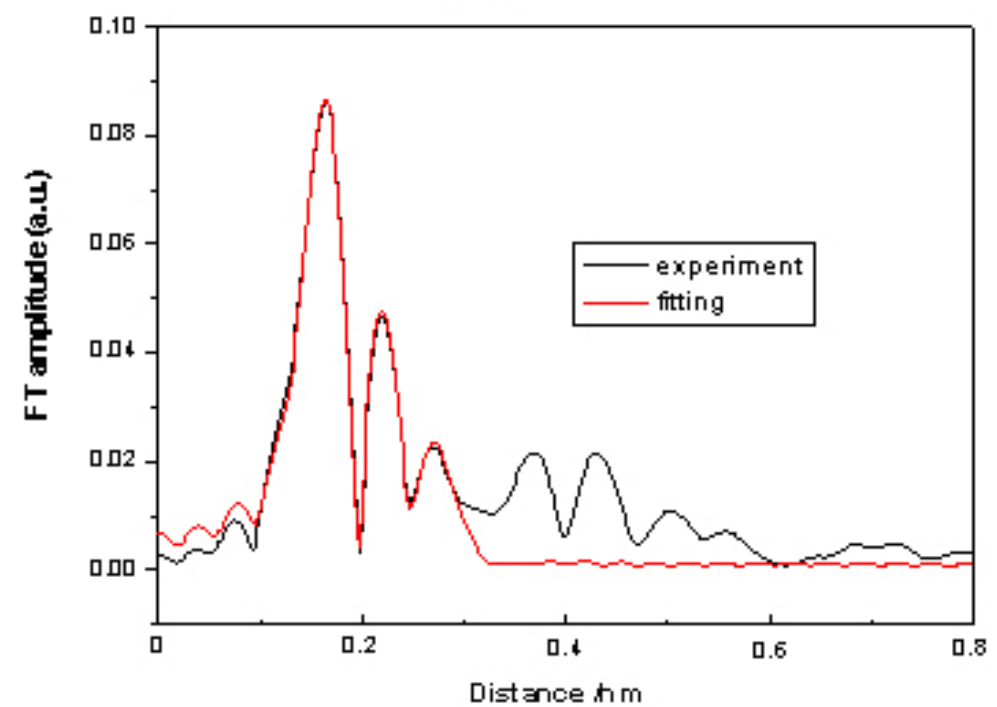

Fig. S2: XAFS signal in R space for the Ni complex nanotubes.

Table S1: Coordination numbers and bond lengths for the first and the second shell of $\mathrm{Ni}\left(\mathrm{NH}_{3}\right)_{6} \mathrm{Cl}_{2}$ derived from the XRD measurements.

\begin{tabular}{|c|c|c|}
\hline $\mathbf{N i}\left(\mathbf{N H}_{3}\right)_{\mathbf{6}} \mathbf{C l}_{\mathbf{2}}$ & $\mathbf{N}$ & $\mathbf{R}(\AA)$ \\
\hline $\mathbf{N i}---\mathbf{N}$ & 6 & 2.120 \\
\hline $\mathbf{N i - - - - C l}$ & 8 & 4.357 \\
\hline
\end{tabular}

Table S2: Fitting results of the coordination numbers and bond lengths for the first and the second shells in the Ni complex nanotubes.

\begin{tabular}{|c|c|c|c|}
\hline $\mathbf{N}$ & $\mathbf{R}(\AA)$ & $\boldsymbol{\sigma}^{2}$ & $\Delta \mathbf{E}_{\mathbf{0}}$ \\
\hline $5.5 \pm 0.4$ & $2.105 \pm 0.010$ & $0.0074 \pm 0.0010$ & $1.46 \pm 2.0$ \\
\hline $1.4 \pm 0.3$ & $2.568 \pm 0.015$ & $0.0078 \pm 0.0015$ & $2.41 \pm 2.0$ \\
\hline $3.4 \pm 0.4$ & $3.060 \pm 0.015$ & $0.0082 \pm 0.0015$ & $5.88 \pm 2.0$ \\
\hline
\end{tabular}

\subsection{Infrared Absorption Spectra}




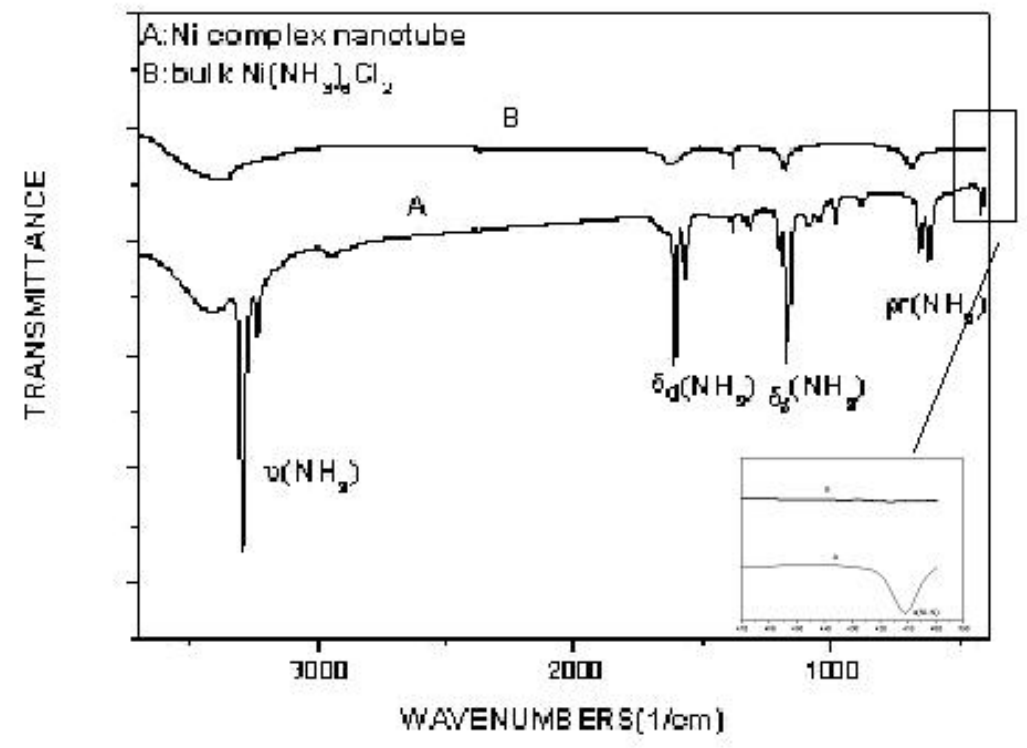

Fig. S3: FTIR spectra of the Ni complex nanotubes (A) and bulk $\mathrm{Ni}\left(\mathrm{NH}_{3}\right)_{6} \mathrm{Cl}_{2}(\mathrm{~B})$.

The comparison of the Fourier Transform Infrared (FTIR) spectra of the Ni complex nanotubes and the bulk $\mathrm{Ni}\left(\mathrm{NH}_{3}\right)_{6} \mathrm{Cl}_{2}$ is shown in Fig. S3. Curve A is the spectrum for the nickel complex nanotubes and curve B is the spectrum of the bulk $\mathrm{Ni}\left(\mathrm{NH}_{3}\right)_{6} \mathrm{Cl}_{2}$. The spectral peaks provide vibrational information of the functional groups in the samples, which is very important for the characterization of the structure and composition of the materials.

From Fig.S3 it can be clearly seen that there is nearly a one-to-one correspondence of the major peaks between the spectra of the $\mathrm{Ni}$ complex nanotubes and the bulk $\mathrm{Ni}\left(\mathrm{NH}_{3}\right)_{6} \mathrm{Cl}_{2}$. In addition, the peak positions are also close in spite of small shifts. This indicates that the functional groups and structures are similar in the two materials. The small spectral shifts may be due to the change from a fcc structure to a tubular structure. As is reported before, $\mathrm{Ni}\left(\mathrm{NH}_{3}\right)_{6} \mathrm{Cl}_{2}$ has four characteristic peaks (Ref. S1): the stretching vibration of $\mathrm{NH}_{3}\left(3400 \square 3000 \mathrm{~cm}^{\square 1}\right)$, the degenerate distortion $(1650 \square$ $\left.1550 \mathrm{~cm}^{\square 1}\right)$, symmetric distortion $\left(1370 \square 1000 \mathrm{~cm}^{\square 1}\right)$, and rocking vibration $\left(950 \square 590 \mathrm{~cm}^{\square 1}\right)$. Our results from both the $\mathrm{Ni}$ complex nanotubes and the bulk complex of $\mathrm{Ni}\left(\mathrm{NH}_{3}\right)_{6} \mathrm{Cl}_{2}$ accord well with the reported data. However, it should be noticed that the peak at a rather low frequency $\left(440 \square 330 \mathrm{~cm}^{\square 1}\right.$ ) in curve A (see also inset) is in good agreement with the reported data of the stretching vibration of $\mathrm{Ni}-\mathrm{N}$ in $\mathrm{Ni}_{(}\left(\mathrm{N}_{2} \mathrm{H}_{4}\right)_{2} \mathrm{Cl}_{2}$ (Ref. S2). To conclude, the FTIR results indicate that the sample mainly consists of $\mathrm{Ni}\left(\mathrm{NH}_{3}\right)_{6} \mathrm{Cl}_{2}$ with some proportion of $\mathrm{Ni}\left(\mathrm{N}_{2} \mathrm{H}_{4}\right)_{2} \mathrm{Cl}_{2}$, which has been inferred from the XRD, EELS, and EXAFS data presented in the main text of the paper and above in the Supporting Information.

\section{S-3. Additional data showing the effect of hydrated $\mathrm{H}_{2} \mathrm{O}$ in $\mathrm{NiCl}_{2} \bullet \mathrm{H}_{2} \mathrm{O}$ and $\mathrm{N}_{2} \mathrm{H}_{4} \bullet \mathrm{H}_{2} \mathrm{O}$ on the Ni complex nanotube formation}

We have testified the effects of the hydrated water by carrying out the same synthesis but using water-free hydrazine but hydrated $\mathrm{NiCl}_{2}$ (Fig. S4) and water-free $\mathrm{NiCl}_{2}$ but hydrated hydrazine (Fig. S5), respectively. No tubes were obtained in Fig. S4 other than pure uniform nickel spheres with diameters of about 300-400 nm. The corresponding XRD pattern of the product is shown in Fig. S5. When using water-free $\mathrm{NiCl}_{2}$ but hydrated hydrazine as shown in Fig. S6, only rod-like products could be seen; the higher magnification image in Fig. S7 shows that the rods are composed of numerous nickel nanoparticles. What is more, when both water-free hydrazine and water-free $\mathrm{NiCl}_{2}$ are used, the products are also of a spherical shape, as shown in Fig. S8. The corresponding XRD pattern is the same as in Fig. S5. 


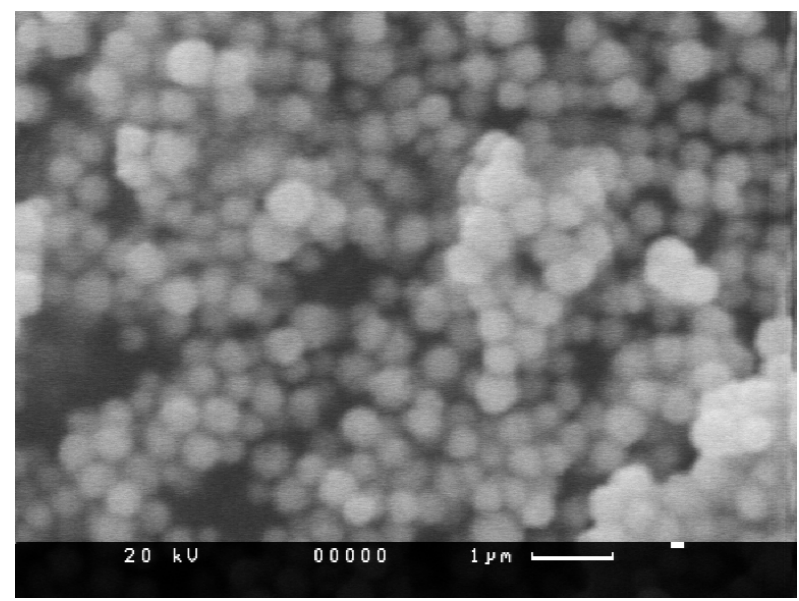

Fig. S4: A SEM image of the products obtained by the same synthesis procedure except for the usage of water-free hydrazine.

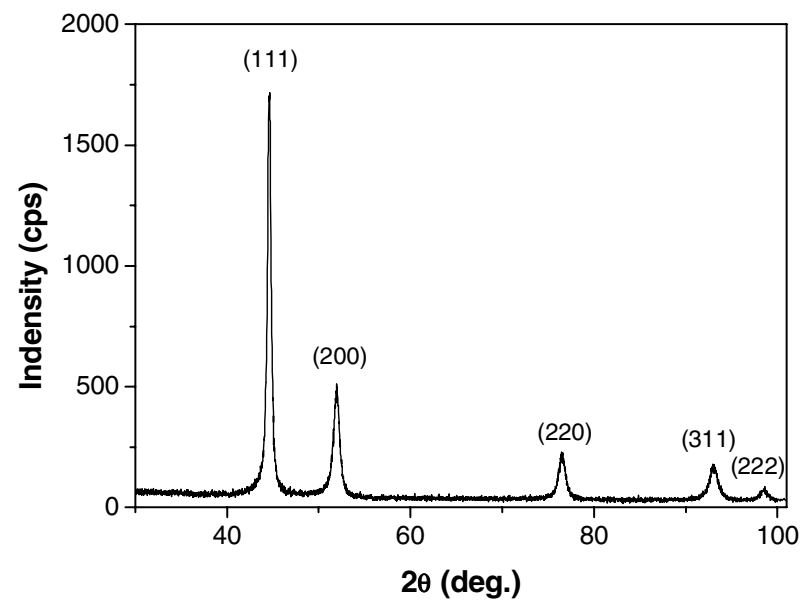

Fig. S5: A XRD pattern of the products obtained by the same synthesis procedure except for the usage of water-free hydrazine. 


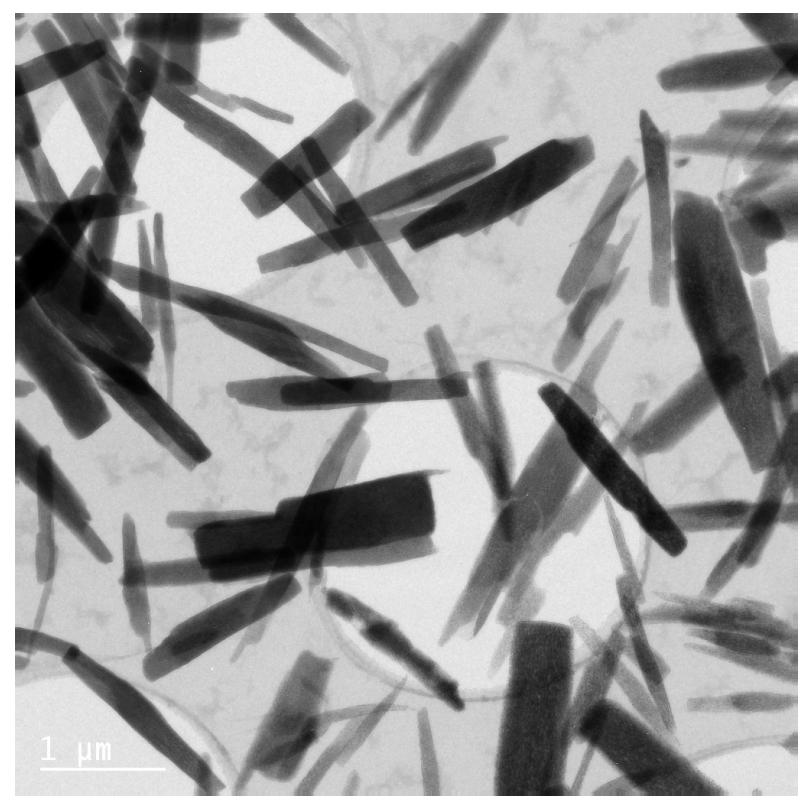

Fig. S6: Low-magnification TEM image of the as-prepared products obtained by the same synthesis procedure except for the usage of water-free $\mathrm{NiCl}_{2}$.

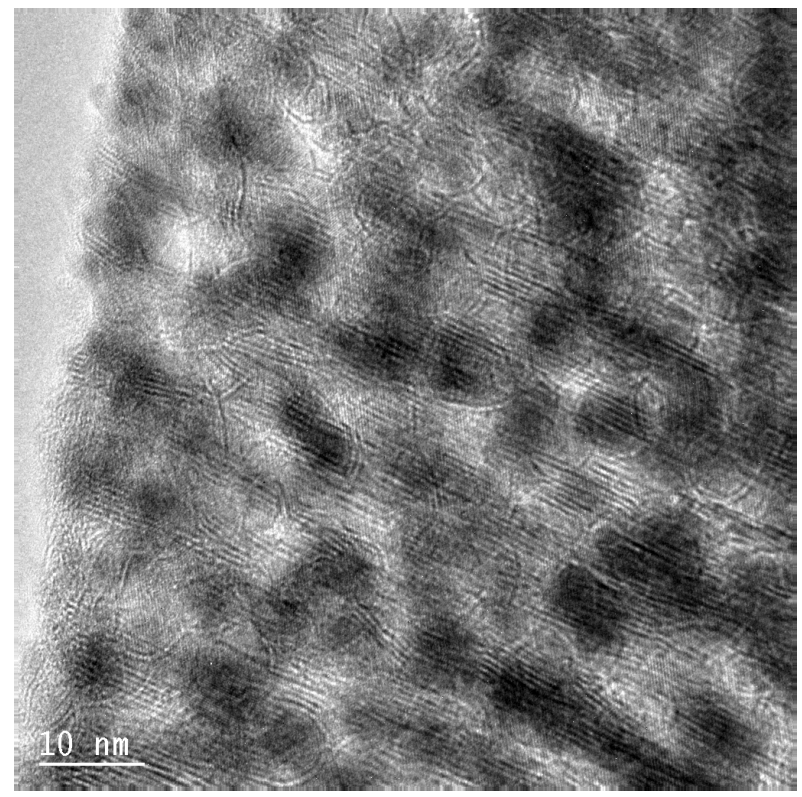

Fig. S7: High-resolution TEM image of the as-prepared products obtained by the same synthesis procedure except for the usage of water-free $\mathrm{NiCl}_{2}$. 


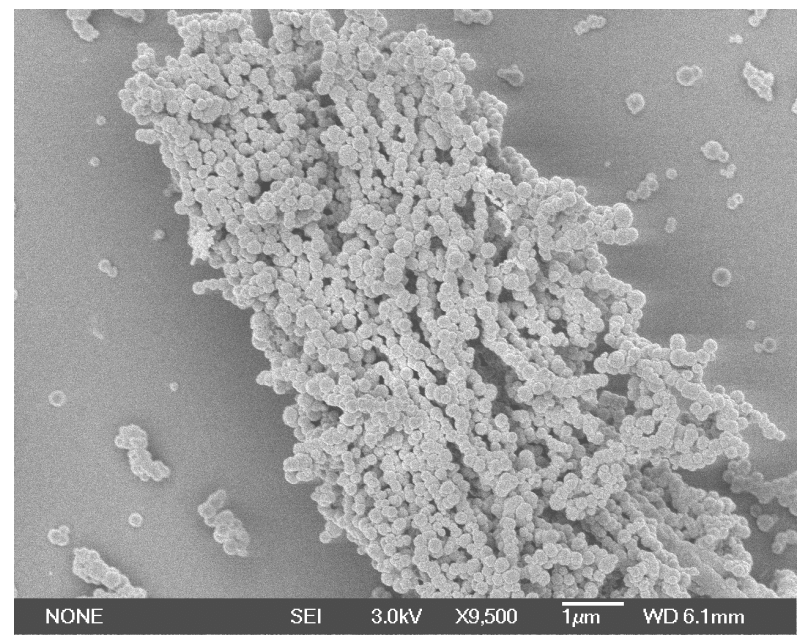

Fig. S8: TEM image of the as-prepared products synthesized with both water-free hydrazine and water-free $\mathrm{NiCl}_{2}$.

\section{S-4. The effect of PVP on the Ni complex nanotube formation}

We have also tried the synthesis of the Ni complex nanotubes without adding PVP. First, similar rod-like violet products were obtained as shown in Fig. S9, but the morphology and size of the products are not as uniform as those synthesized in the presence of PVP. Second, the diameters of the nanorods are about $80-150 \mathrm{~nm}$, which are much larger than those of the nanotubes modified by PVP. Third, the as-prepared product without PVP is very unstable in ambience and the color turned from violet to green after 2-hour exposure in the air, indicating the decomposition of the complex. However, the Ni complex nanotubes modified with PVP are stable even after 3-month exposure in the air.

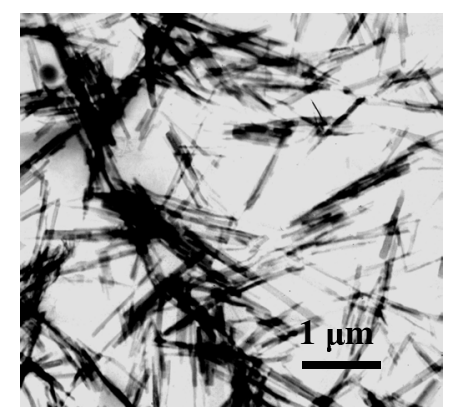

Fig. S9: TEM image of the products obtained by the same synthesis procedure except without PVP.

\section{S-5. The decomposition of $\mathrm{Ni}\left(\mathrm{N}_{2} \mathrm{H}_{4}\right)_{2} \mathrm{Cl}_{2}$}

As we have described in the text of the paper, the decomposition of $\mathrm{Ni}_{(}\left(\mathrm{N}_{2} \mathrm{H}_{4}\right)_{2} \mathrm{Cl}_{2}$ is slow; the diffraction peaks of $\mathrm{Ni}\left(\mathrm{N}_{2} \mathrm{H}_{4}\right)_{2} \mathrm{Cl}_{2}$ are still appreciable even after $5 \mathrm{~h}$ of reflux. Further experiments have been done to verify this conclusion. When the refluxing time increases, the diffraction peaks of the $\mathrm{Ni}\left(\mathrm{N}_{2} \mathrm{H}_{4}\right)_{2} \mathrm{Cl}_{2}$ decrease obviously. However, the intensities of these diffraction peaks do not disappear even after more than $24 \mathrm{~h}$ refluxing, as is shown in Fig. S10. 


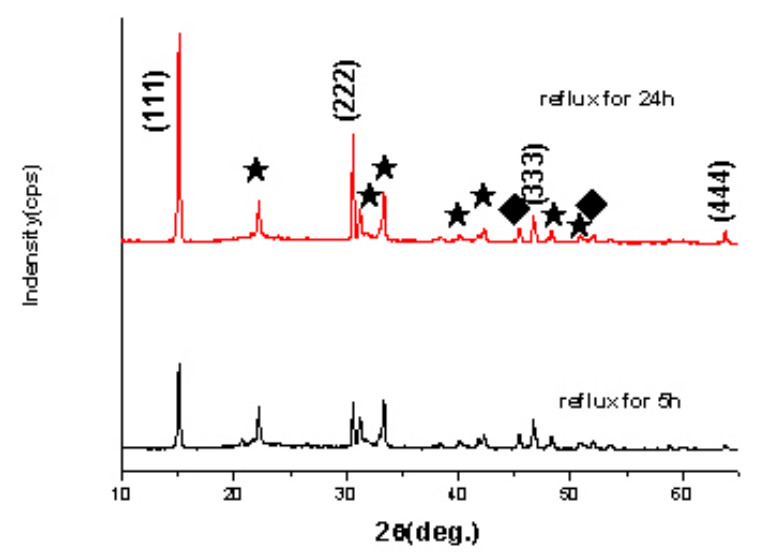

Fig. S10: XRD patterns of the Ni complex nanotubes after different refluxing times.

\section{References:}

S1. K.H. Schmidt, A. Muller, Coord. Chem. Rev. 1976, 19, 41.

S2. D. Nicholls, R. Swindells, J. Inorg. Nucl. Chem. 1968, 30, 2211. 